\title{
Tecnologia lítica, cronologia e sequência de ocupação: o estudo de um sítio a céu aberto na região de Lagoa Santa, MG
}

BUENO, L. Tecnologia lítica, cronologia e sequência de ocupação: o estudo de um sítio a céu aberto na região de Lagoa Santa, MG. Revista do Museu de Arqueologia e Etnologia, São Paulo, 20: 91-107, 2010.

Resumo: A região de Lagoa Santa tem sido foco de estudos arqueológicos desde a primeira metade do século XIX. Conhecida pela presença recorrente de sepultamentos humanos, ocupações em abrigo sob-rocha e uma cronologia que remonta ao início da ocupação humana no Brasil, essa região tem apresentado, nos últimos anos, evidências também de uma ocupação a céu aberto, com datas disponiveis para outros periodos ao longo do Holoceno. Neste texto exploramos os dados referentes a um desses sítios, principalmente no que diz respeito ao conjunto lítico a ele associado. A partir desses dados discutimos seu processo de ocupação e a cronologia obtida, inserindo o sítio numa sistema dinâmico de ocupação do carste da Lagoa Santa.

Palavras-chave: Lagoa Santa - Tecnologia litica - Sitio a céu-aberto.

\section{Introdução}

A região de Lagoa Santa tem sido estudada do ponto de vista paleontológico e arqueológico desde a primeira metade do século XIX (Hrdlicka 1912; Mattos 1946; Walter 1958; Hurt 1960; Hurt e Blasi 1969; Laming-Emperaire et al. 1975; Neves e Pilo 2008). Esse interesse, no entanto, não se traduziu na existência de uma pesquisa de longa-duração, sistemática e ininterrupta na região até recentemente. Apesar disso, há atualmente dezenas de sitios arqueológicos identificados e certamente centenas a serem

${ }^{*}$ )Laboratório de Estudos Evolutivos Humanos. Instituto de Biologia da Universidade de São Paulo - IB-USP. Bolsista Pós-doutorado FAPESP <lmrbueno@usp.br> descobertos, a maioria deles correspondendo a abrigos sob-rocha. Isso é particularmente significativo para o periodo mais antigo da região, que remonta, em alguns sítios, ao final do Pleistoceno e início do Holoceno (Araujo et al. 2005, Araujo e Pugliese 2009; Hurt e Blasi 1969; Laming-Emperaire et al. 1975; Neves et al. 2003, 2004, 2008). Até o momento, sítios a céu aberto representam uma absoluta exceção para a ocupação referente à transição Pleistoceno/ Holoceno. Esse padrão se inverte quando se foca o periodo mais recente, vinculado a ocupações ceramistas que ocupam majoritariamente áreas abertas (Neves et al. 2004).

Essa baixa representatividade de sítios a céu aberto relacionados aos periodos de ocupação mais antigos não é exclusividade da região de Lagoa Santa e em parte pode ser decorrente da estratégia de prospecção 
comumente utilizada no país, mas envolve também uma série de outros aspectos, como caracteristicas dos vestígios arqueológicos dos diferentes periodos em termos qualitativos e quantitativos, natureza e intensidade dos processos naturais de formação de sitio e ocupação atual do terreno.

Recentemente o projeto "Origens"1 investiu no sentido de esclarecer essa peculiaridade do contexto arqueológico regional, intensificando os trabalhos de prospecção a céu aberto em grandes profundidades e abrindo a possibilidade de inserção de novos elementos para a compreensão da dinâmica da ocupação antiga de Lagoa Santa. Através dessa iniciativa uma série de sítios a céu aberto tem sido identificada, principalmente no entorno das lagoas cársticas que abundam na região. Os sítios encontrados até agora apresentam caracteristicas diversificadas entre si com relação à composição, extensão e cronologia, havendo indícios de ocupação do entorno das lagoas ao longo de todo o Holoceno (Neves et al. 2004; Neves et al. 2008).

Neste artigo apresento os dados relativos a um desses sitios, composto basicamente por vestigios líticos com datas associadas ao Holoceno Inicial, Médio e Recente, localizado às margens da Lagoa do Sumidouro.

\section{O sítio Coqueirinho}

\subsection{Implantação}

O sítio Coqueirinho está implantado às margens da Lagoa do Sumidouro, na base de uma vertente de inclinação suave com direção NW-SE que define um patamar ligeiramente plano antes de uma queda acentuada na declividade decorrente da ação erosiva provocada pela flutuação do nível de água da lagoa (Fig.1).

(1) Projeto "Origens e Microevolução do Homem na América: uma abordagem paleoantropológica" coordenado por Walter Neves no Laboratório de Estudos Evolutivos Humanos, IB/USP e financiado pela FAPESP 2000-2009.
Nessa área de inflexão do declive da vertente aflora uma linha de cascalho composta por fragmentos de quartzo leitoso de veio, mas com algumas arestas arredondadas e seixos de tamanhos variados. Essa linha de erosão representa o nivel máximo da linha d'água, aparece em vários pontos no entorno da lagoa e invariavelmente apresenta vestígios arqueológicos associados.

O conjunto de vestígios arqueológicos associados ao sítio é composto majoritariamente por material lítico, mas há também vestigios de material histórico, como telhas, pregos e fragmentos de arame, principalmente nos niveis mais superficiais. Os vestigios arqueológicos aparecem desde a superfície até cerca de 70 $\mathrm{cm}$ de profundidade.

\subsection{Intervenções}

Em função dessa configuração - com evidências de material em superfície e em profundidade - essa área foi selecionada para realização de tradagens e sondagens ainda durante as etapas de prospecção no entorno da Lagoa do Sumidouro realizadas entre os anos de 2001 a 2003 (Neves et al. 2004). Foram realizadas sete tradagens, das quais uma foi ampliada para realização de uma sondagem.

Em julho de 2008 as atividades no sitio foram retomadas com a realização de cinco novas sondagens. Com o objetivo de caracterizá-lo melhor com relação à cronologia absoluta, sequência de ocupação e caracteristicas tecnológicas da indústria litica, optei por abrir uma série de sondagens no que parece ser uma área de concentração de vestígios, ao invés de tentar delimitar sua área total de dispersão. Assim, um dos objetivos principais das intervenções foi obter novas amostras de material lítico associado a estruturas de combustão que viabilizassem a obtenção de novas datas para estabelecimento de uma cronologia adequada.

Para a realização desses objetivos defini uma malha de sondagens estreita, distribuindoas em espaços regulares de $5 \mathrm{~m}$. As sondagens foram abertas de forma sequencial e distribuidas em dois eixos paralelos (Fig.2). Todas foram escavadas por niveis artificiais de $10 \mathrm{~cm}$, atingindo profundidades máximas entre 1,60 a 2,0m. 


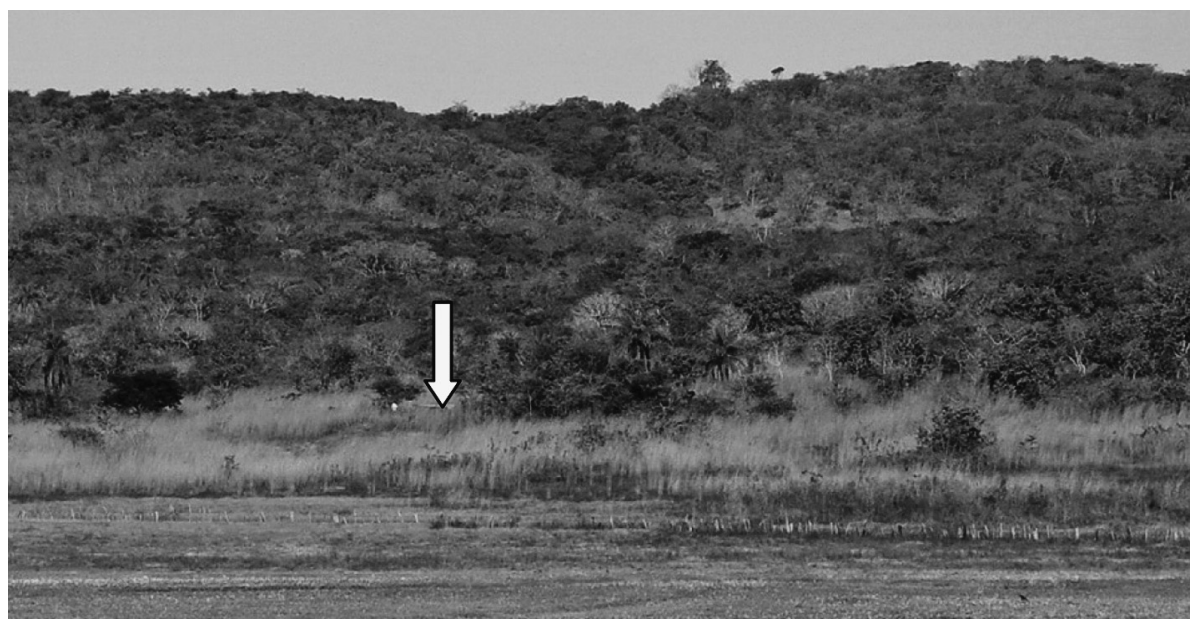

Fig. 1. Implantação do sítio Coqueirinho. Serra ao fundo, seguida por vertente suave onde está assentado o sítio Coqueirinho e, à frente, parte da Lagoa do Sumidouro seca em julho de 2009 (Foto Lucas Bueno).

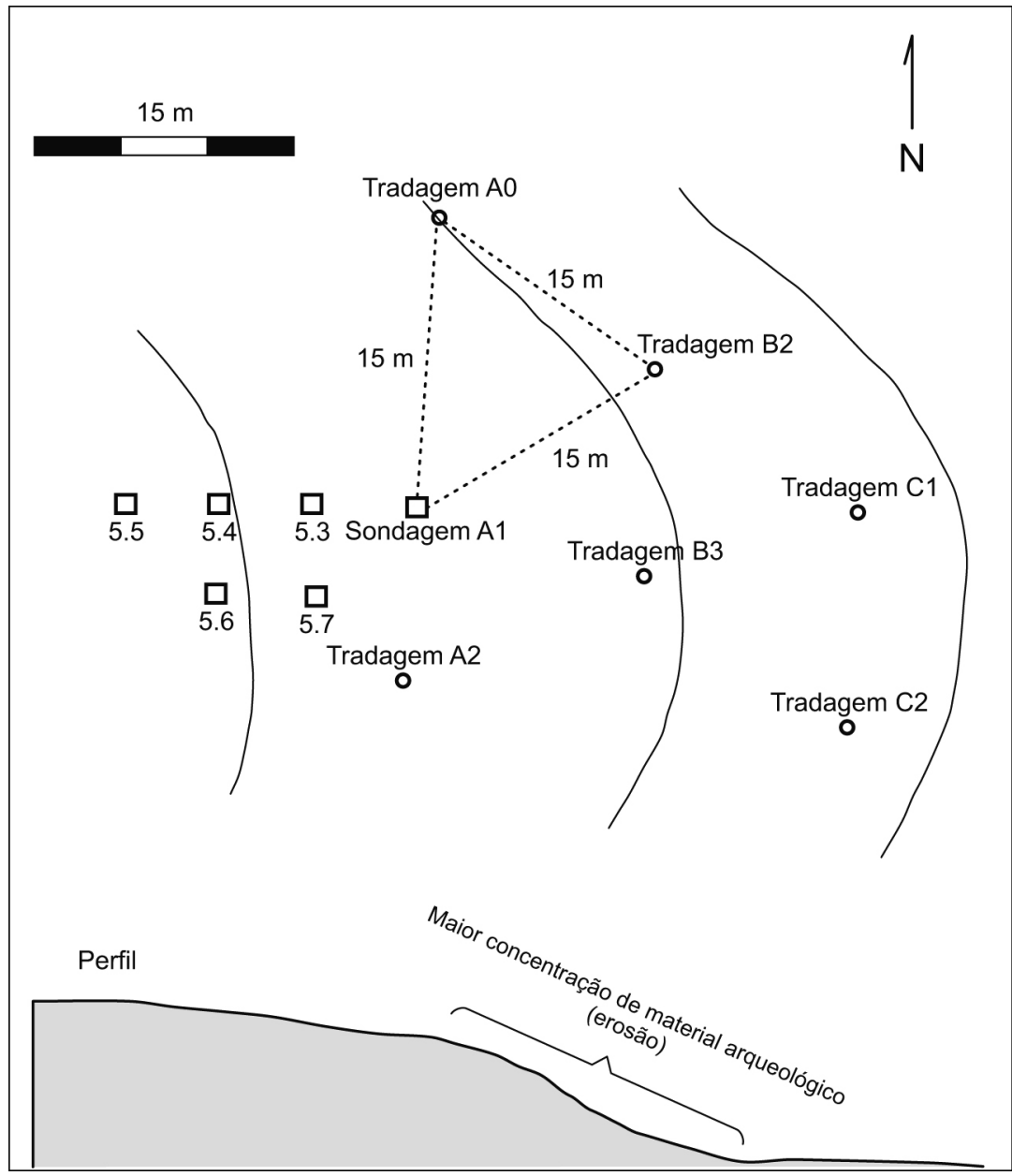

Fig. 2. Planta esquemática da localização das intervenções realizadas no sítio Coqueirinho e perfil topográfico de sua implantação (adaptado de Neves et al. 2004, fig.2.18). 
Com essas intervenções consegui ampliar a amostra de material litico, bem como identificar e coletar carvão de diferentes sondagens e niveis para datação. Com relação à questão de tamanho e forma da área de dispersão de vestigios, há algumas hipóteses e dúvidas que devem ser encaminhadas com o prosseguimento da pesquisa.

\subsection{Composição e estratigrafia}

Como pode ser visto na Fig. 3 as sondagens com maior número de vestígios são respectivamente $1,4,3$ e 7 , enquanto aquelas com menor número de vestígios são 5 e 6 . Embora a amostra seja ainda muito reduzida, tanto no que se refere ao espaço investigado quanto ao total de vestígios coletados (385), essa distribuição restringe a área de concentração à borda da vertente na qual se insere o sitio, coincidindo com o local de maior impacto do processo erosivo. No entanto, como já mencionado, a área abrangida por essas sondagens certamente corresponde a uma fração muito reduzida do sítio, uma vez que a área cobre apenas $20 \times 7 \mathrm{~m}\left(140 \mathrm{~m}^{2}\right)$. Foram identificados em superfície ao menos dois locais de concentração de vestigios distantes cerca de $100 \mathrm{~m}$ entre si, definindo uma área de dispersão com potencialmente $1.000 \mathrm{~m}^{2}$ (Fig.4).

Com relação à distribuição vertical dos vestigios o conjunto de intervenções realizadas aponta para a existência de uma concen- tração entre os niveis 4 e 5 da estratigrafia, com algumas variações em cada sondagem (Fig. 5). Apesar dessas variações não há em nenhuma delas indicação de dois ou mais niveis de concentração intercalados por uma diminuição na quantidade de vestígios. Apesar de terem sido identificadas evidências de movimentação vertical dos vestígios, devido à atuação de processos naturais pósdeposicionais, principalmente bioturbações provocadas por cupins e formigas, essa convergência vertical da concentração dos vestigios entre as diferentes sondagens aponta para a possibilidade de existência de ao menos um nivel de ocupação bem definido para o sitio em torno dos $50 \mathrm{~cm}$ de profundidade.

Com relação à estratigrafia quatro camadas distintas foram identificadas. A mais profunda é representada por um sedimento amarelo argiloso que aparece também na "base" de sondagens realizadas em outros pontos no entorno da Lagoa do Sumidouro, mas que no Coqueirinho se apresenta mosqueada por intrusões de um sedimento mais amarronzado. Acima dela ocorre uma camada marrom misturada com uma camada de conglomerado formado por seixos e fragmentos de pequeno porte. Sobreposta a ela há uma camada de sedimento marrom escuro que corresponde aos niveis onde aparece mais material arqueológico. Ainda na sequência, ocorre uma camada de sedimento marrom que segue até à superfície, à qual

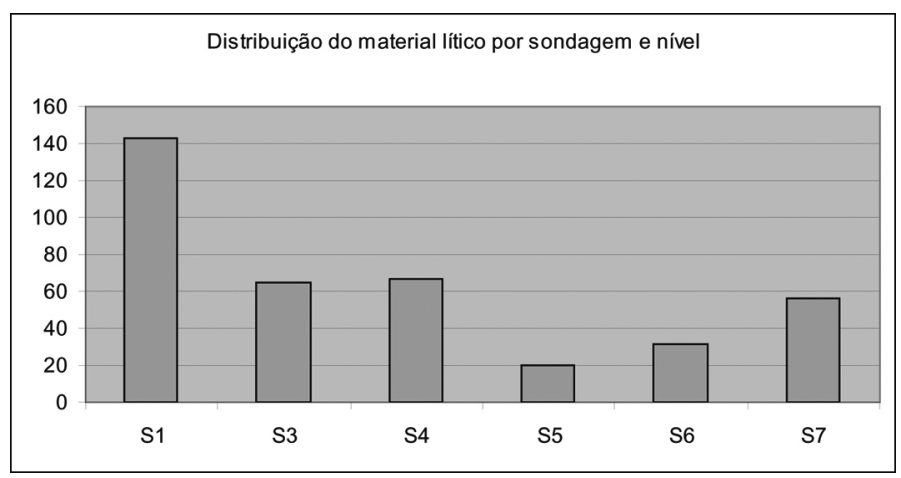

Fig. 3. Distribuição da quantidade total de vestígios liticos por sondagem no sítio Coqueirinho. 


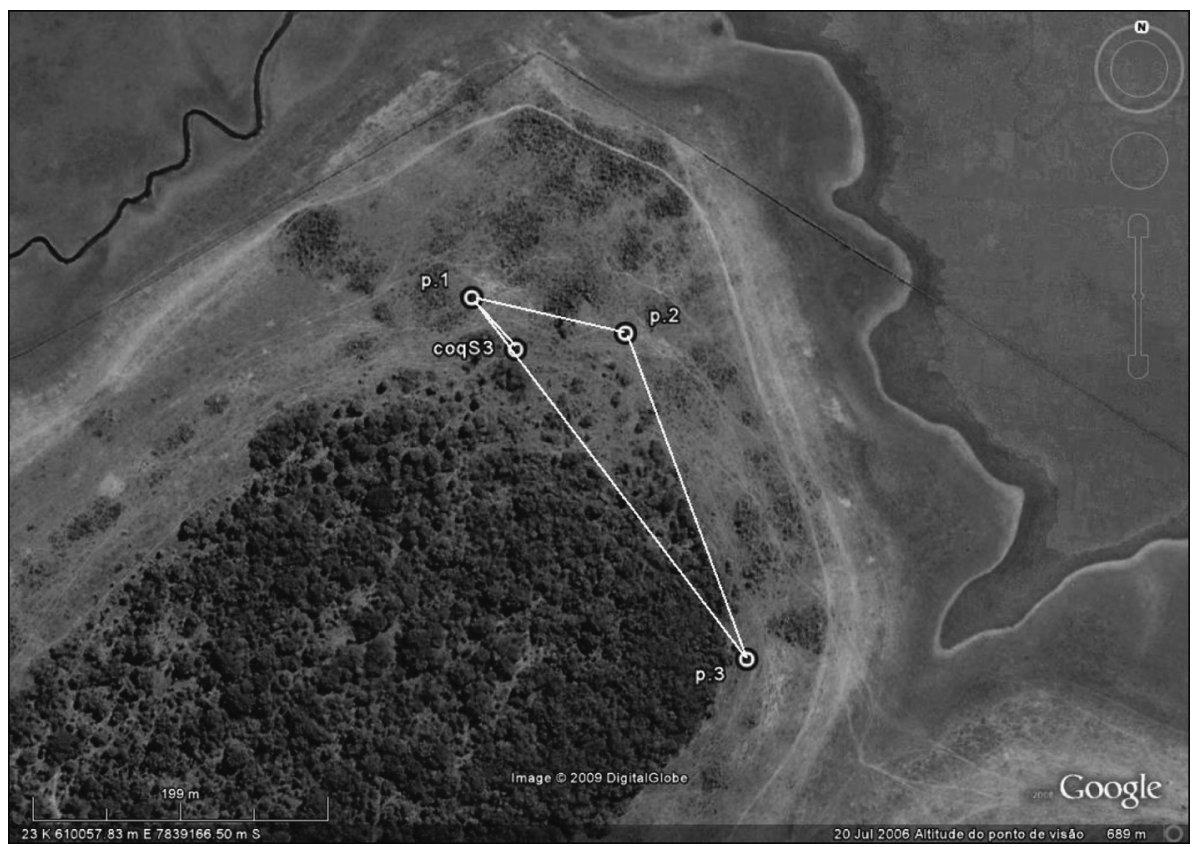

Fig. 4. Imagem de satélite indicando a extensão máxima da distribuição do material litico em superficie no sitio Coqueirinho.

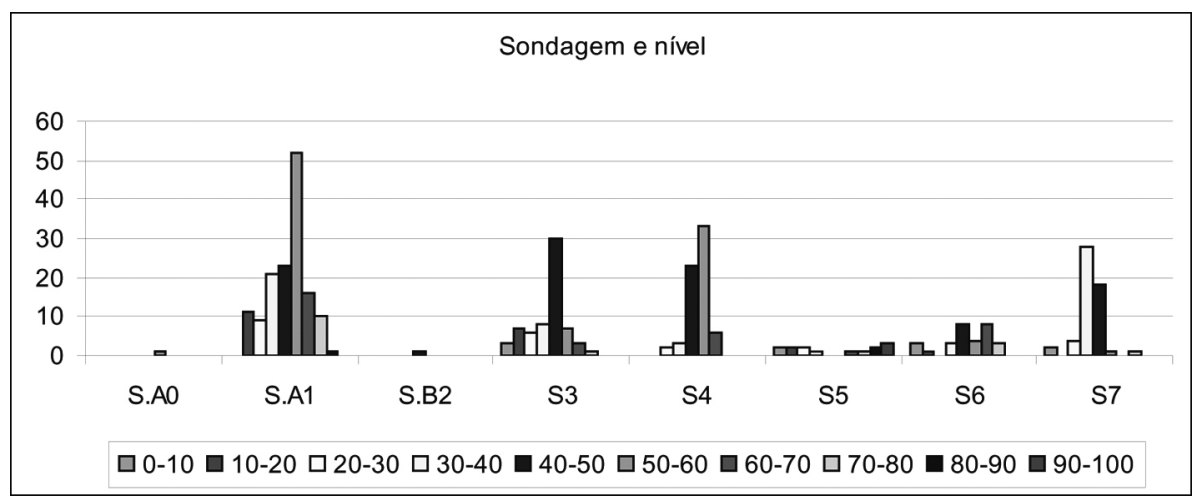

Fig. 5. Distribuição do material lítico por sondagem e nivel no sítio Coqueirinho.

está associado o material histórico encontrado no sítio. Há entre as sondagens algumas variações quanto à espessura dessas camadas e o nivel exato em que aparecem, mas em geral a sequência se mantém (Fig.6).

\section{Cronologia}

Até o momento foram obtidas para este sitio cinco datações pelo método radiocarbônico e uma pelo método de luminescência opticamente estimulada, conforme apresentado na Tabela 1 .

De acordo com a distribuição estratigráfica dos resultados obtidos fica evidente uma inversão na relação entre profundidade das amostras e datas, provavelmente relacionadas à atuação de processos pós-deposicionais na movimentação vertical dos vestigios.

Todas as amostras, à exceção da COQ-1648, foram coletadas em associação direta com 


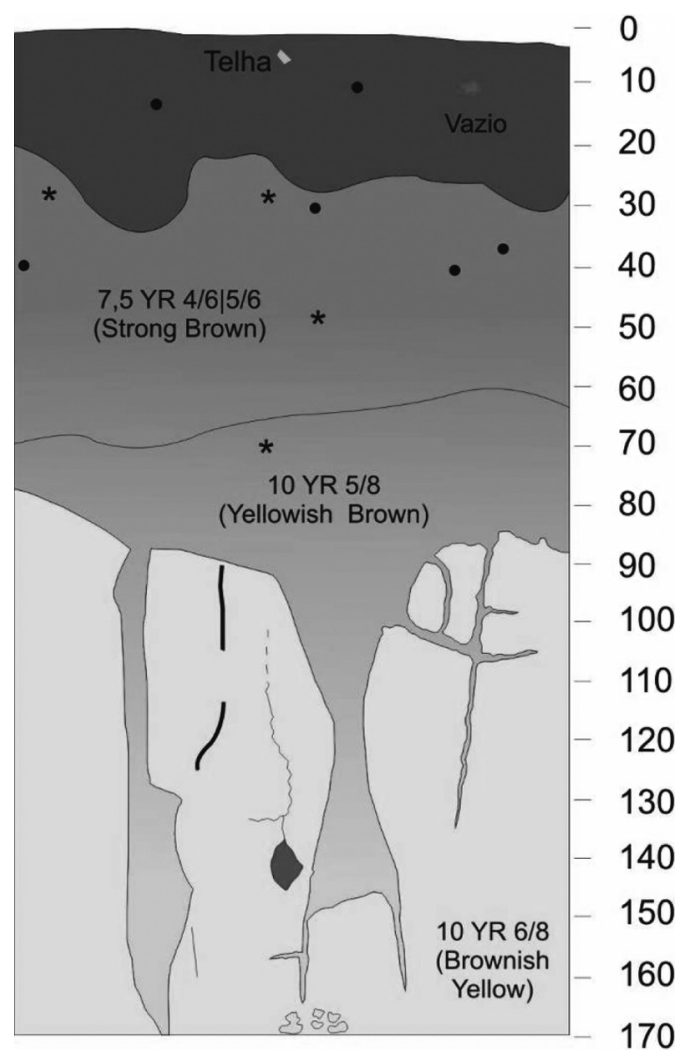

Fig. 6. Perfil estratigráfico do perfil oeste da sondagem 3 (Desenho de Andre Strauss).

vestigios arqueológicos, muito embora não tenhamos identificado no sítio nenhuma estrutura de combustão bem definida e articulada. Os carvões que compõem as amostras datadas foram obtidos através de coletas pontuais in situ ou agrupados por nivel no caso de amostras individuais muito pequenas.

Se, apesar das inversões identificadas, considerar-se a associação entre as amostras datadas e o material arqueológico coletado no sítio, pode-se sugerir a existência de ao menos cinco diferentes periodos de ocupação no local: 1. uma ocupação inicial contemporânea às primeiras ocupações dos abrigos, do final do Pleistoceno e datada em 10.460 anos AP; 2. uma segunda ocupação no Holoceno Médio, com data por volta dos 6.800 anos AP; 3. uma terceira ocupação no Holoceno Recente, com datas entre 3.800 e 3.600 anos AP; 4. uma quarta ocupação ainda no Holoceno Recente e anterior às primeiras ocupações associadas à presença de cerâmica na região, datada em 2.700 anos AP; e, por último, 5. uma ocupação recente do sítio, contemporânea à nossa era, datada em 100 anos antes do presente.

Esse quadro hipotético, que considera a associação entre carvões-vestígios arqueológicos e associa as datas obtidas a periodos distintos de ocupação do sítio, necessita ser testado através do cruzamento de uma série de outros dados baseados em evidências independentes.

Neste artigo, dou encaminhamento a essa questão através da análise tecnológica e da distribuição vertical dos vestigios liticos. É possivel, através dessa metodologia, identificar diferentes conjuntos liticos no sitio? Para responder a essa questão fiz uma caracterização tecnológica desses vestígios, investigando a distribuição e correlação de um conjunto de atributos em estratigrafia.

\section{A indústria lítica}

Para caracterização da indústria lítica do Coqueirinho fiz uma análise que

Tabela 1

Localização das amostras datadas para o sítio Coqueirinho

\begin{tabular}{|c|c|c|c|c|c|c|c|}
\hline Amostra & Material & Beta & Sondagem & Nível & $\begin{array}{c}\text { Idade } \\
\text { Radiocarbônica }\end{array}$ & $\begin{array}{l}\text { Calibragem } 2 \\
\text { Sigmas }\end{array}$ & c12/c13 \\
\hline COQ - 1624 & carvão & 248885 & S.6 & $40-50 \mathrm{~cm}$ & $3.790 \pm 40$ & 4290 a 4010 & $-25.9 \mathrm{o} / \mathrm{oo}$ \\
\hline COQ - 1190 & carvão & 237346 & S.1 & $50-60 \mathrm{~cm}$ & $10.460 \pm 60$ & 12690 a 12090 & $-25.1 \mathrm{o} / \mathrm{oo}$ \\
\hline COQ - 1628 & carvão & 248886 & S.6 & $70-80 \mathrm{~cm}$ & $3.620 \pm 40$ & 4080 a 3840 & $-24.9 \mathrm{o} / \mathrm{oo}$ \\
\hline COQ - 1630 & carvão & 248887 & S. 6 & $70-80 \mathrm{~cm}$ & $2.740 \pm 40$ & 2930 a 2760 & $-25.8 \mathrm{o} / \mathrm{oo}$ \\
\hline COQ - 1631 & carvão & 248888 & S. 6 & $80-90 \mathrm{~cm}$ & $6.800 \pm 50$ & 7700 a 7580 & $-25.5 \mathrm{o} / \mathrm{oo}$ \\
\hline COQ - 1648 & carvão & 248889 & S. 4 & $160-170 \mathrm{~cm}$ & $100 \pm 40$ & 280 a 0 & $-27.4 \mathrm{o} / \mathrm{oo}$ \\
\hline
\end{tabular}


envolve a distribuição estratigráfica de um conjunto de atributos em três escalas. Em um primeiro momento, foquei atributos gerais como matéria prima, categoria, dimensão e grau de preservação dos vestígios, a fim de verificar a existência de variações na composição do conjunto que possam estar relacionadas ao desenvolvimento de atividades distintas (Shott 1994, Sullivan e Rozen 1985). Em um segundo momento, analisei atributos mais especificos relacionados aos gestos, designs e performances selecionadas no processo de confecção e utilização dos artefatos (Bueno 2007). Por último, fiz uma caracterização das sequências operatórias identificadas e de sua distribuição estratigráfica.

\subsection{Matéria Prima}

Conforme mostra a Fig. 7 a matéria prima preponderante no sítio é o quartzo hialino, uma vez que aparece mais bem representada em todos os niveis. Quartzo (leitoso) e quartzito aparecem na sequência, mas com uma representatividade muito inferior ao primeiro. O que se percebe com relação à distribuição da matéria prima na estratigrafia é a definição de um conjunto entre 20 e $70 \mathrm{~cm}$ de profundidade que responde pela diversidade deste atributo, com uma intensificação na quantidade de vestigios de cada matéria prima entre $40 \mathrm{e}$ $60 \mathrm{~cm}$. Com relação ao silex e ao arenito silicificado, matérias primas comumente associadas às ocupações mais antigas da região (Araújo e Pugliese 2009), pode-se destacar a presença de arenito silicificado exclusivamente nos niveis 5,6 e 7 e a baixa representatividade do silex no conjunto dos vestígios liticos.

\subsection{Conjunto de vestígios}

Seguindo tendência identificada na Fig. 7, também para o caso da distribuição vertical dos tipos de vestigio tem-se um incremento da diversidade das categorias entre 20 e $70 \mathrm{~cm}$, com uma clara concentração entre 40-60 cm. Predominam de uma forma geral, em todos os níveis, as lascas e apesar da exiguidade dos conjuntos por nível há, na maioria deles (entre o nivel 1 e o nível 8 ), artefatos. Por outro lado, em todo o conjunto do sitio foi identificado apenas um núcleo.

Com relação à dimensão dos vestígios predominam em todos os niveis aqueles cuja

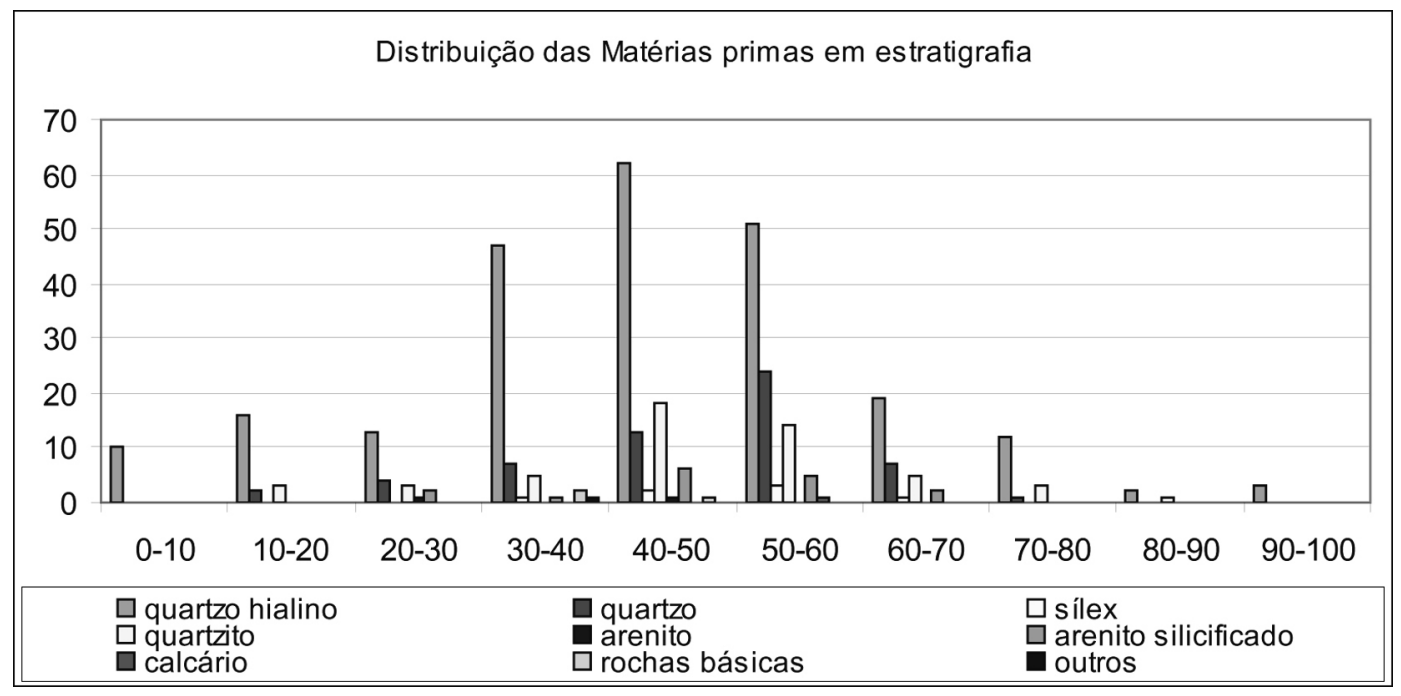

Fig. 7. Distribuição das matérias primas por nivel no sitio Coqueirinho. 


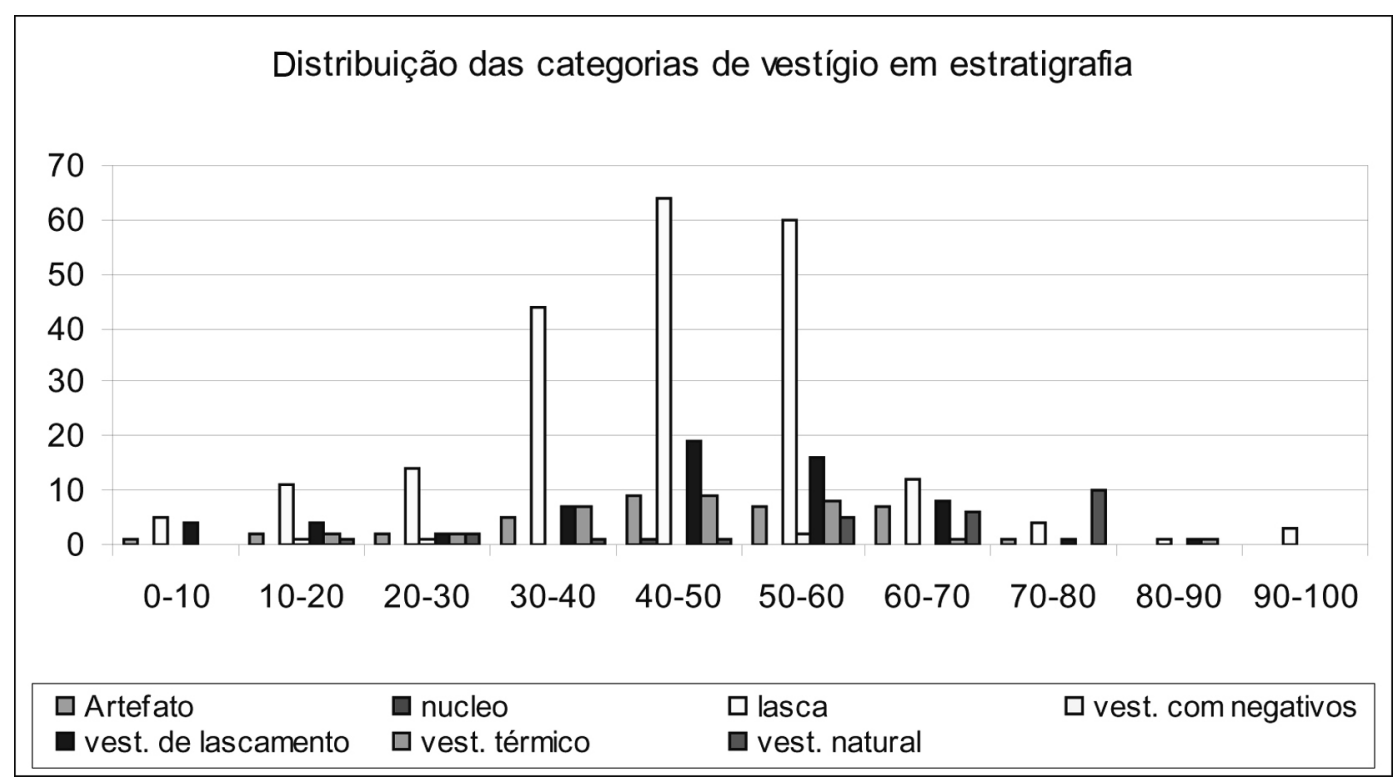

Fig. 8. Distribuição das categorias de vestigio por nivel para o sítio Coqueirinho.

dimensão máxima ${ }^{2}$ está entre 1 e $2 \mathrm{~cm}$. Da mesma forma como para os atributos anteriores, a maior diversidade aparece entre 20-70 $\mathrm{cm}$, intervalo este que corresponde também aos niveis nos quais se têm amostras mais numerosas (aparentemente não há, no entanto uma correlação forte entre diversidade e tamanho da amostra). Como a tecnologia litica é eminentemente redutiva, informações sobre os suportes selecionados para lascamento são necessárias para se discutir o significado das dimensões identificadas para a maioria dos vestigios: corresponderiam eles a estágios finais de redução, retoque e reavivagem?; ou seriam os suportes selecionados de pequenas dimensões?

Com relação ao grau de preservação dos vestigios vê-se que em todos os niveis predominam os vestigios fragmentados que no total respondem por cerca de $69 \%$ dos liticos coletados no sitio.

Quando as duas informações - dimensões e graus de preservação - são levadas em consideração nota-se que não há muita alteração na distribuição geral das categorias de tamanho,

(2) Neste gráfico incluimos todos os vestigios analisados independentemente do seu grau de preservação. a não ser pela baixa representatividade de vestigios com dimensões inferiores a $1 \mathrm{~cm}$ entre os que estão inteiros. Entre os inteiros continuam a predominar os que apresentam dimensões entre 1 e $2 \mathrm{~cm}(46 \%)$, seguidos pelos entre $2 \mathrm{e}$ $3 \mathrm{~cm}(26 \%)$ e entre 3 e $4 \mathrm{~cm}$ (15\%).

Para os quatro atributos gerais analisados ocorre uma distribuição estratigráfica muito semelhante: aumento da diversidade de variáveis observadas em cada atributo entre os niveis 2 e 7, com uma tendência de incremento dessa diversidade nos niveis 4 e 5 . Apesar de não haver estatisticamente uma correlação significativa entre essa variabilidade e o tamanho dos conjuntos de cada nivel, os niveis 4 e 5 são também aqueles que apresentam os maiores conjuntos de vestigios no Coqueirinho.

$\mathrm{O}$ único aspecto que merece destaque nessa distribuição por ser potencialmente indicativo de variações tecnológicas é a presença de arenito silicificado exclusivamente nos niveis 5, 6 e 7. Ou seja, a partir dessa caracterização geral da coleção não há elementos suficientes que justifiquem a distinção de conjuntos tecnológicos diferenciados ao longo da estratigrafia.

Para refinar esta caracterização, atributos mais especificos que têm uma relação direta 


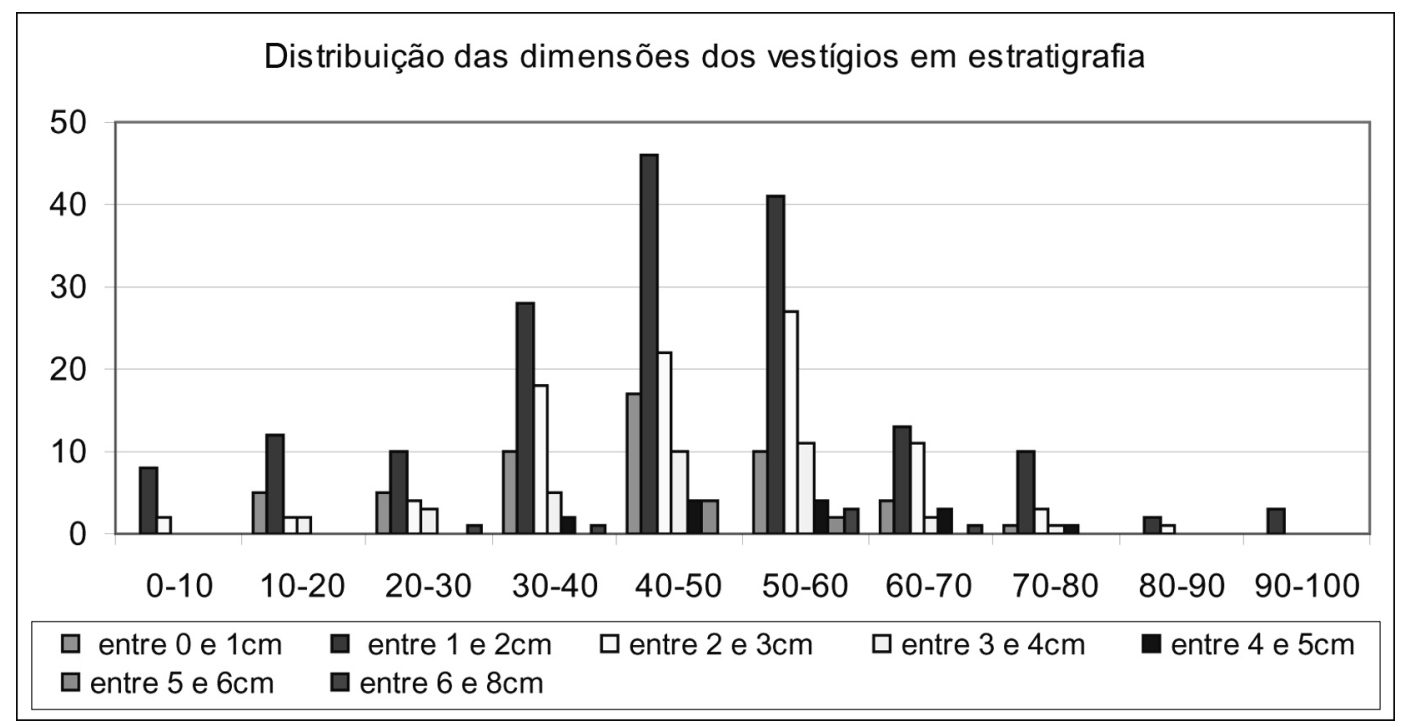

Fig. 9. Distribuição das dimensões dos vestigios por nivel para o sítio Coqueirinho.

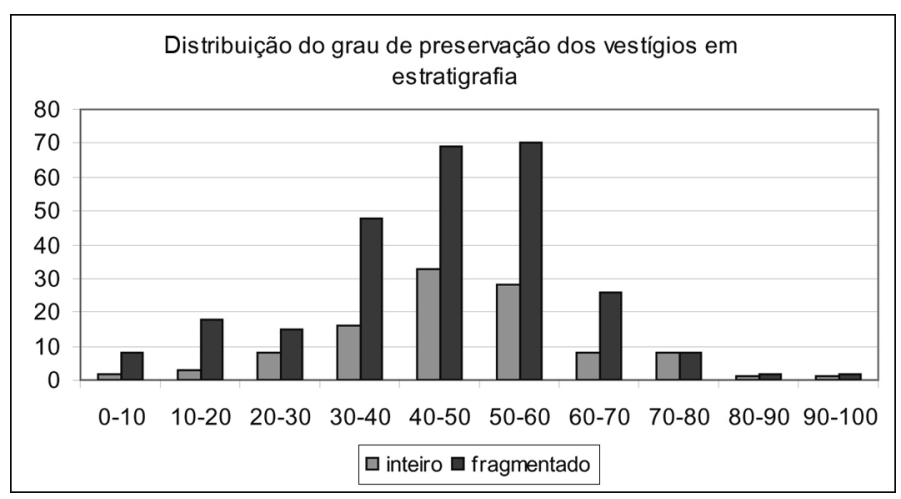

Fig. 10. Distribuição do Grau de preservação dos vestigios por nivel para o sitio Coqueirinho.

com gestos e escolhas efetuadas ao longo das diversas etapas que envolvem a procura, a obtenção, a produção, o uso, a circulação e o descarte dos artefatos líticos podem ser analisados.

\subsection{Artefatos}

Como já mencionamos há artefatos em todos os niveis com uma concentração entre o $5^{\circ}$. e o $7^{\circ}$ (Fig.11). Todos os artefatos foram produzidos por percussão unipolar, à exceção de dois percutores sobre seixo de quartzito. $\mathrm{O}$ suporte preferencialmente utilizado foi a lasca, novamente com a única exceção relacionada aos percutores. Com relação ao grau de preservação, predominam os artefatos inteiros (64\%), seguidos respectivamente por aqueles com quebra transversal (25\%) e longitudinal (11\%). Predominam também os artefatos com vestigios corticais (63\%).

Com relação à matéria prima, a maioria dos suportes utilizados para confecção dos artefatos envolveu lascas de quartzo hialino (Fig.12). Quartzito, quartzo leitoso e sílex estão presentes também na amostra, mas com baixissima representatividade.

Comparando-se as dimensões dos artefatos com as das lascas, para saber se estas 


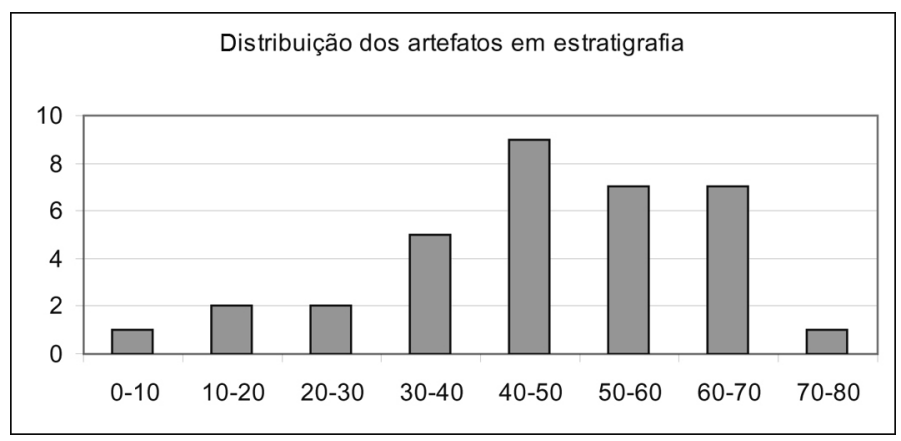

Fig. 11. Distribuição da quantidade total de artefatos por nivel para o sitio Coqueirinho.

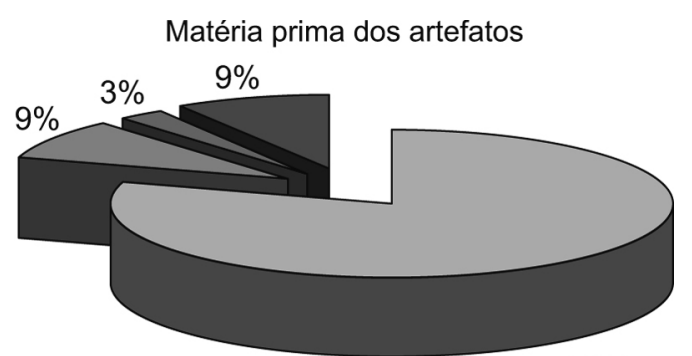

$79 \%$

$\square$ quartzo hialino $\square$ quartzo $\square$ silex $\quad \square$ quartzito

Fig. 12. Frequência das matérias primas utilizadas para produção de artefatos no sítio Coqueirinho.

seriam suporte para artefatos ou se seriam destacadas a partir deles no processo de confecção e utilização, pode-se dizer que ambas as opções são plausiveis. Se, por um lado, há uma distribuição diferencial entre lascas e artefatos, por categoria de tamanho (como indica a Tabela 2), por outro há uma baixa incidência de transformações secundárias sobre os artefatos, o que geraria poucas lascas de retoque, indicando ao mesmo tempo, uma diferença reduzida entre dimensão inicial e final dos artefatos encontrados no sítio.

Ainda com relação à dimensão, dos três artefatos com maiores dimensões, dois são percutores - um para lascamento unipolar e outro para lascamento uni e bipolar - sendo ambos seixos de quartzito. O terceiro, com dimensão máxima de $7,8 \mathrm{~cm}$, também foi confeccionado em seixo de quartzito, mas tem como suporte uma lasca e apresenta características peculiares quando comparado aos demais artefatos da coleção (Tabela 2).

\section{Tabela 2}

Frequência de artefatos, lascas e vestígios em geral por intervalos de dimensão

\begin{tabular}{cccc}
\hline \hline $\begin{array}{c}\text { Dimensão } \\
\text { máxima }\end{array}$ & Artefatos (\%) & Lascas (\%) & Geral (\%) \\
\hline $1(0-1 \mathrm{~cm})$ & 3 & 16 & 14 \\
$2(1-2 \mathrm{~cm})$ & 26 & 50 & 45 \\
$3(2-3 \mathrm{~cm})$ & 38 & 24 & 24 \\
$4(3-4 \mathrm{~cm})$ & 21 & 6 & 9 \\
$5(4-5 \mathrm{~cm})$ & 3 & 3 & 4 \\
$6(5-6 \mathrm{~cm})$ & - & 1 & 2 \\
$7(6-8 \mathrm{~cm})$ & 9 & - & 2 \\
$8(8-10 \mathrm{~cm})$ & - & - & 8 \\
Total & 100 & 100 & 100 \\
\hline
\end{tabular}

Outros aspectos que podem ser mencionados no tocante à associação entre lascas e artefatos envolvem a relação entre dimensões e número de gumes, bem como entre dimensões e intensidade de retoque. No primeiro caso constata-se que os artefatos cujas dimensões estão entre 2 e 4 cm são ao mesmo tempo os que apresentam maior intensidade de retoques e os únicos com presença de 2 ou 3 gumes. No entanto, nem todos os artefatos com essas dimensões envolvem necessariamente esse tipo de configuração, prevalecendo dentre o intervalo aqueles com apenas 1 gume e baixa intensidade de retoque (Tabela 3 ). 
Tabela 3

Distribuição dos artefatos por quantidade de gumes e intervalos de dimensão

\begin{tabular}{lcccc}
\hline \hline & 1 gume & 2 gumes & 3 gumes & Total \\
\hline $0-1 \mathrm{~cm}$ & 1 & - & - & 1 \\
$1-2 \mathrm{~cm}$ & 7 & - & - & 7 \\
$2-3 \mathrm{~cm}$ & 9 & 2 & 1 & 12 \\
$3-4 \mathrm{~cm}$ & 3 & 1 & 1 & 5 \\
$4-5 \mathrm{~cm}$ & 1 & - & - & 1 \\
$5-6 \mathrm{~cm}$ & - & - & - & - \\
$6-8 \mathrm{~cm}$ & 1 & - & - & 1 \\
Total & 22 & 3 & 2 & 27 \\
\hline
\end{tabular}

Esta é, aliás, uma caracteristica que se aplica à maioria dos artefatos da coleção. Como mostra a Tabela 3, dos 27 artefatos inteiros apenas dois tem três gumes e três têm dois gumes, com o restante (22) apresentando apenas um gume. Proporção semelhante ocorre com relação à intensidade do retoque: sete artefatos com mais de duas sequências de retiradas e $20 \mathrm{com}$ duas ou apenas uma sequência (Tabela 4). Ou seja, no geral, esta é uma indústria com artefatos de pequeno porte e com baixa intensidade de transformação secundária. No entanto, é preciso reforçar que a atividade de retoque e reavivagem está presente e, em alguns artefatos, indica uma intensificação na utilização com incremento da vida útil.

A relação entre técnica de preensão e número de gumes ou extensão de retoques indica que os artefatos utilizados através de preensão direta correspondem àqueles que apresentam maior intensidade de modificação secundária e também maior número de gumes. Ou seja, encabamento não está necessariamente associado à vida-útil dos artefatos, mas provavelmente ao desempenho da atividade para a qual o artefato é utilizado.

Este é um aspecto importante, pois indica uma escolha relacionada não só aos gestos efetuados no desempenho da atividade relacionada aos artefatos, mas também à priorização de um determinado desempenho em seu design e à associação entre diferentes tipos de material no processo de produção dos instrumentos. Tal conjunto de associações pode ser utilizado como um bom indicador da relação entre escolha, performance e design e, se observarmos a distribuição dessas características na estratigrafia tem-se ainda a informação de que esta não é homogênea, prevalecendo entre os artefatos dos niveis 5 e 6 . Neste sentido, vale a pena mencionar que é também nestes niveis (incluindo ai também os niveis 4 e 7) que predominam os artefatos fragmentados no eixo transversal e, dentre os inteiros, aqueles com Comprimento $>$ largura ou Comprimento $=$ largura, aspectos característicos de artefatos encabados.

Como visto anteriormente não há, entretanto, uma relação direta entre encabamento e intensidade de retoque ou número de gumes, aspectos que parecem estar mais diretamente relacionados aos instrumentos utilizados por preensão direta. Além da relação com a forma de preensão, intensidade de retoque e número de gumes são atributos associados a artefatos que apresentam também uma distribuição diferencial na estratigrafia. Em ambos os casos,

Tabela 4

Distribuição dos artefatos por tipo e sequência de retoque e intervalos de dimensão

\begin{tabular}{lccccccc}
\hline \hline & N.Ident. & Mil. & Mil./Marg. & Marg./Inv. & Mil./Marg/Inv. & Mil./Marg./Inv./Env. & Total \\
\hline $0-1 \mathrm{~cm}$ & - & - & 1 & - & - & - & 1 \\
$1-2 \mathrm{~cm}$ & 3 & 2 & 2 & - & - & - & 7 \\
$2-3 \mathrm{~cm}$ & 1 & 1 & 5 & - & 4 & 1 & 12 \\
$3-4 \mathrm{~cm}$ & 1 & 1 & - & 1 & 1 & 1 & 5 \\
$4-5 \mathrm{~cm}$ & - & 1 & - & - & - & - & 1 \\
$5-6 \mathrm{~cm}$ & - & - & - & - & - & - & - \\
$6-8 \mathrm{~cm}$ & & - & 1 & - & - & - & 1 \\
Total & 5 & 5 & 9 & 1 & 5 & & 27 \\
\hline
\end{tabular}


nota-se que é só nos niveis 4, 5, 6 e 7 que ocorrem artefatos com sequências de três ou quatro retoques e artefatos com dois ou três gumes.

Com base neste conjunto de informações pode-se esboçar tanto uma caracterização dos artefatos do Coqueirinho quanto uma possivel diferenciação dos mesmos ao longo da estratigrafia. No entanto, conforme já frisado, esta oposição deve ser testada através da ampliação da amostra e da inclusão de novas evidências independentes.

De um modo geral, no que diz respeito aos artefatos, predomina uma indústria litica caracterizada pela produção de instrumentos pequenos e com poucas modificações secundárias, aos quais se somam artefatos com caracteristicas peculiares, que envolvem reavivagem intensa, multifuncionalidade e preensão indireta.

Essas caracteristicas peculiares, por sua vez, estão diretamente relacionadas a três aspectos cruciais na elaboração do artefatual litico: gestos, performances e design (Bueno 2007). Como visto, a elaboração de artefatos encabados requer gestos específicos tanto no processo de confecção quanto de utilização, os quais são guiados por uma performance determinada que requer um design especifico - encabamento, neste caso, não está relacionado diretamente à intensificação de uso, mas provavelmente a uma performance especifica. A esses aspectos deve-se ainda somar a interação requerida por essa técnica com outros tipos de matérias primas, como, por exemplo, madeira e osso, obtidos e manuseados segundo outros procedimentos.

Dois aspectos mencionados anteriormente merecem ainda mais atenção por indicarem também uma baixa intensidade de transformações secundárias do suporte: o fato de a maioria dos artefatos estar inteira e apresentar ainda reserva cortical.

Assim, apesar de haver uma série de evidências que indicam uma baixa intensidade de transformação secundária dos suportes para confecção dos artefatos, é interessante observar que praticamente inexistem núcleos na coleção; ou estes foram transportados para outros locais ou foram debitados até se esgotarem. Se se optar pela segunda alternativa, pode-se dizer que há uma certa intensificação na utilização da matéria prima nesta indústria, mas que ela está no outro extremo da cadeia operatória na exploração dos núcleos e não na re-utilização e reavivagem dos artefatos. Esse procedimento pode estar relacionado a escolhas orientadas segundo razões ligadas a diferentes esferas, mas ao menos uma delas, relacionada à conexão entre design e performance, pode ser explorada.

Como se vê na Tabela 4, a maioria dos artefatos da coleção apresenta dimensões diminutas e retoques predominantemente marginais ou milimétricos. Essas dimensões diminutas envolvem não só comprimento e largura, mas também espessura, ou seja, são artefatos cujo volume é pequeno. Este é um ponto fundamental na tomada de decisão relacionada à possibilidade de reavivagem ou não, uma vez que peças com volumes pequenos apresentam restrições técnicas à reestruturação. Nesse sentido, cabe discutir a razão da elaboração de artefatos com tais restrições. Uma das possibilidades envolve a confecção de artefatos compostos, produzidos através de um certo tipo de encabamento ou incrustação dos microartefatos em hastes ou suportes de outra natureza, como madeira e/ou osso, tal qual ocorre, por exemplo, no mesolitico europeu (Myers 1989).

Neste caso, ocorre uma exploração intensa de núcleos com o intuito de fornecer lascas de diferentes tamanhos que serão incorporadas na produção de artefatos que respondem a diferentes performances. Lascas maiores, mais compridas do que largas, de formato trapezoidal são selecionadas para confecção de artefatos com gume distal mais robusto, podendo ou não ser encabadas e, eventualmente, reavivadas até seu total esgotamento; lascas também mais compridas do que largas, mas com forma retangular ou elíptica, selecionadas para definição de gumes lineares extensos, são utilizadas na preensão direta; lascas pequenas, com menos de $2 \mathrm{~cm}$ de comprimento e $0,5 \mathrm{~cm}$ de espessura, são utilizadas para definição de pequenos gumes com modificações marginais, 
possivelmente encabadas, formando artefatos compostos. Este conjunto de artefatos, distribuidos de acordo com a morfologia, entendida aqui como volume do suporte original, se aplica, de forma mais apropriada, ao quartzo, principalmente o hialino, mas não esgota a utilização desta matéria prima, havendo outras categorias de artefato na indústria do Coqueirinho. Os retoques efetuados para transformação do suporte são preferencialmente diretos, mas há casos também da aplicação de retoques alternantes e alternados no conjunto analisado.

As demais matérias primas, como silex, quartzito e arenito silicificado apresentam uma representatividade muito baixa na categoria dos artefatos para que se possam definir sequências operatórias relacionadas à sua exploração, mas é em silex que um fragmento bifacial de ponta de projétil foi encontrado no sítio.

\subsection{Sequências operatórias}

Para o lascamento do cristal de quartzo o método mais comum utilizado no Coqueirinho envolve a aplicação de um golpe inicial próximo à crista, com percusão direta, utilizando-se percutor duro. O golpe produz uma lasca espessa que inclui toda a parte referente ao ápice do cristal e um núcleo composto pelas faces laterais e raiz do cristal. Este núcleo pode ser lascado a partir de três procedimentos distintos que se intercalam de acordo com a morfologia do cristal e a qualidade do quartzo (espessura, distância entre as arestas e comprimento do cristal são alguns dos elementos que influenciam a opção entre os três procedimentos). Tais procedimentos envolvem: 1. retiradas orientadas pelas arestas longitudinais do cristal, utilizando-se como plataforma de lascamento o negativo deixado pela retirada inicial; 2 . retiradas orientadas para a face do cristal, com intercalação na direção do lascamento e exploração do cristal segundo seu eixo longitudinal, utilizando como plataforma de lascamento o negativo deixado pela retirada inicial; 3 . retiradas orientadas para a face do cristal, explorando-o no seu eixo transversal, utilizando como plataforma de lascamento uma de suas faces. Excepcionalmente, o procedimento 3 pode ser utilizado para "abrir" o cristal.

Para exploração da lasca de ápice de cristal utiliza-se o mesmo conjunto de procedimentos, mas pode ocorrer também sua utilização bruta ou com pequenos retoques, configurando um dos tipos de artefato presentes na coleção do Coqueirinho.

Tais sequências produzem lascas com morfologias distintas e são intercaladas na exploração do cristal, não havendo uma sucessão rigida em sua aplicação. Em todos os niveis estratificados foram encontradas lascas oriundas dessas sequências.

Embora poucas lascas de arenito silicificado fino tenham sido encontradas, há um conjunto delas oriundo de uma mesma sequência operatória relacionada à preparação e retoque de artefatos plano-convexos, todas localizadas entre os niveis 6 e 7 (Fig.13).

O quartzito, na maioria das vezes oriundo da exploração de seixos, mostra predominância de núcleos piramidais, com plataforma cortical e lascamento em uma única direção. As lascas oriundas desse processo aparecem exclusivamente nos niveis 5 e 6 .

O silex, conforme já mencionado, está pouco representado na coleção, mas aparece na forma de uma ponta de projétil que, apesar de fragmentada, indica lascamento bifacial e utilização combinada de diferentes técnicas: percussão macia e pressão (Fig.14). Além da ponta de projétil ocorre ainda uma lasca em silex, possivelmente associada ao lascamento bifacial. Assim como no caso do quartzito, as lascas de silex predominam nos niveis 5 e 6 .

\section{Discussão}

Com base na análise tecnológica pode-se dizer que há variações em diferentes escalas: 1 . há um padrão geral com pequenas variações, sendo a principal delas a distribuição diferencial de determinadas matérias primas, especificamente o arenito silicificado fino; 2 . há a produção de um conjunto de artefatos que apesar de oferecer um panorama de homogeneidade à primeira vista, esconde algumas variações importantes 


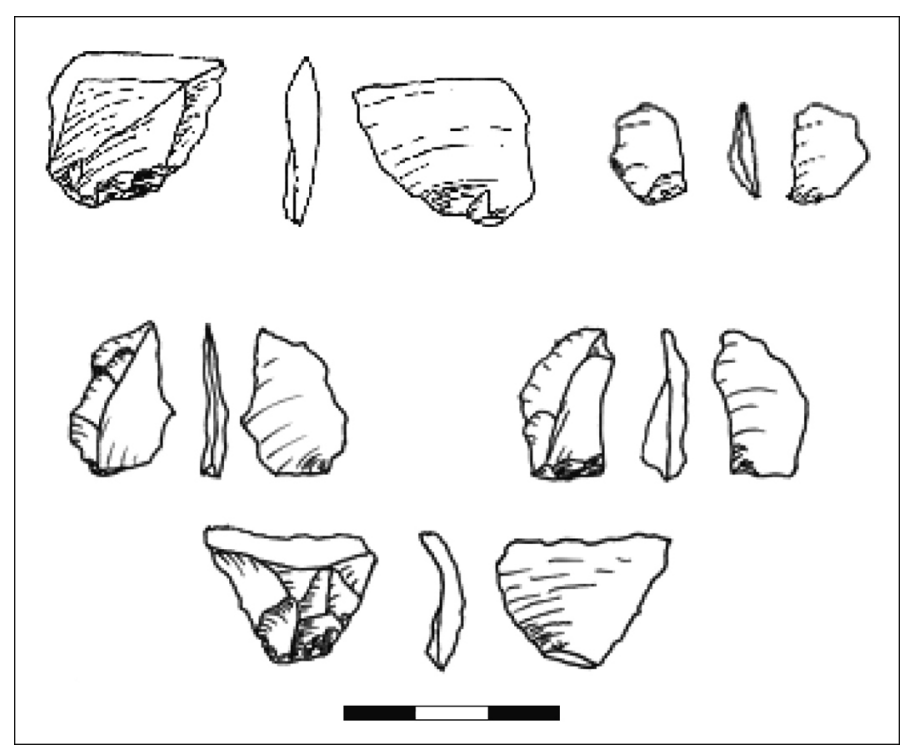

Fig. 13. Lascas de arenito silicificado fino possivelmente associada a formatação e retoque de artefatos plano-convexos (Desenho Lucas Bueno).

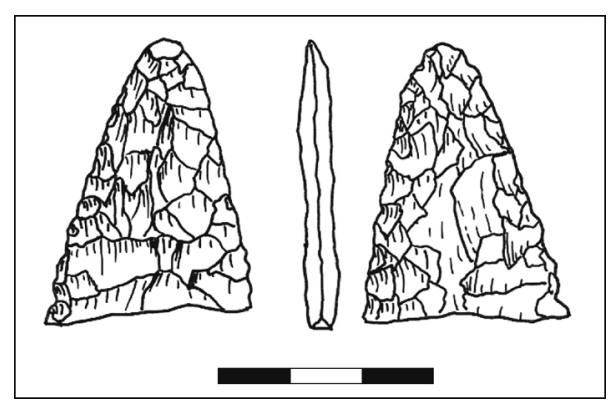

Fig. 14. Fragmento de ponta de projétil em silex. (desenho Lucas Bueno)

no que diz respeito aos gestos envolvidos tanto na produção quanto na utilização, às performances e aos designs selecionados; ou seja, há um tratamento diferencial da mesma matéria prima em função de performances distintas, requerendo designs especificos, obtidos através de sequências operacionais bem definidas; 3 . para o tratamento da mesma matéria prima há sequências operatórias distintas e às vezes complementares, e há sequências distintas para diferentes tipos de matéria prima. Assim, apesar de ser relativamente pequena, a coleção litica do Coqueirinho aponta para a existência de variações na estratégia de composição e gestão do conjunto artefatual.
Com relação à distribuição estratigráfica dos vestigios líticos foi possivel identificar algumas variações que apontam para a existência de ao menos dois conjuntos. Um primeiro, formado pelos niveis mais profundos, a partir de cerca de $50 \mathrm{~cm}$ de profundidade, no qual é encontrada maior diversidade de matérias primas e de artefatos, com variações na forma de preensão, intensidade de redução e utilização destes últimos; e um segundo formado pelos niveis mais superficiais, com um conjunto menos denso, composto majoritariamente por vestígios de quartzo hialino, com predominância de um único tipo de artefato, caracterizado por baixa intensidade de redução sobre suportes de pequenas dimensões. 
Estes dois macro-conjuntos não resolvem a questão da associação e da distribuição das datações obtidas para o sítio, uma vez que o principal conjunto está representado pelos vestigios localizados nas camadas para as quais resultados bastante dispares foram obtidos. Isso faz com que seja necessário não só continuar os trabalhos de escavação a fim de ampliar ainda mais a amostra e obter novas datações, mas também, e talvez principalmente, discutir essa questão a partir da incorporação de novas evidências independentes do material litico.

Neste sentido, com relação ao material litico resta uma questão fundamental: a variabilidade tecnológica observada no conjunto é decorrente de uma composição mista, que engloba vestigios de diferentes momentos de ocupação, ou indica a existência de uma ocupação especifica com estratégias distintas no processo de apropriação do material lítico? Ou seja, a análise tecnológica aponta para a existência concomitante de uma diversidade de formas de exploração do quartzo e de sua relação com as demais matérias primas, mas não gera informações suficientes para distinguir ou dissociar essa diversidade no tempo. Dessa maneira, a análise aqui realizada corrobora, reforça a questão inicial levantada pela distribuição das datações absolutas obtidas para este sítio: conjuntos de evidências muito diversas agrupados em um mesmo espaço.

Como mencionado, para atacar tal questão é necessário incluir novas evidências, tais como micromorfologia e sequências completas de datações do sedimento. Outra estratégia seria a inclusão de novos sítios, com cronologias culturais mais bem definidas e passiveis de serem utilizadas como referência para desmembramento dos sítios no entorno da Lagoa do Sumidouro no tempo e no espaço.

Para tanto é preciso, por sua vez, atacar questões fundamentais no que diz respeito a certas características tecnológicas da indústria litica do sítio Coqueirinho: qual a estratégia envolvida na adoção de uma hierarquia de performance que prioriza seleção de artefatos de pequeno porte, exploração intensiva de núcleos, baixo indice de reavivagem, produção de artefatos compostos? A discussão desta questão, aliada à análise de outras coleções liticas provenientes tanto de sítios a céu aberto quanto de abrigos, contribuirá não só para uma melhor compreensão do sítio Coqueirinho, mas, principalmente, para avançarmos na caracterização do processo de ocupação da região de Lagoa Santa ao longo do Holoceno.

Com base nas informações disponiveis pode-se pleitear a existência de estratégias distintas na composição dos conjuntos líticos identificados. A existência de matérias primas exógenas ao carste de Lagoa Santa, como o arenito silicificado e o sílex, por exemplo, indicaria um deslocamento ou contato mais acentuado com áreas adjacentes. A identificação de lascas associadas a atividades de retoque e reavivagem de artefatos unifaciais ausentes na coleção sugere fortemente o transporte e utilização de determinadas categorias de artefato em outros pontos da paisagem. $\mathrm{O}$ mesmo pode ser dito com relação à ponta de projétil bifacial em silex coletada no sitio, para a qual não há nenhuma evidência relacionada à sua fabricação e manutenção. A caracterização da utilização combinada de material litico com outros tipos de matéria prima, como madeira e osso, para confecção de artefatos compostos, indica uma associação direta entre sistemas tecnológicos distintos e complementares, envolvendo planejamento e antecipação na obtenção e preparo das matérias primas utilizadas. Todos estes aspectos têm sido extensamente debatidos na arqueologia norte-americana como possiveis correlatos para diferentes estratégias de subsistência e mobilidade entre caçadores-coletores, desde os trabalhos seminais de L. Binford na década de 1970 (Binford 1979, 1980). A continuação da análise, com ampliação da coleção do Coqueirinho e inserção de coleções oriundas de sitios em abrigo certamente levarão a um avanço nesta discussão, caracterizando as estratégias aqui esboçadas e dissociando-as no tempo, se for o caso, a fim de construir interpretações confiáveis acerca da dinâmica de ocupação da região de Lagoa Santa numa perspectiva diacrônica. 
BUENO, L. Lithic Technology, chronology and occupation sequence: the study of an open-air site in the Lagoa Santa region, MG, Brazil. Revista do Museu de Arqueologia e Etnologia, São Paulo, 20: 91-107, 2010.

Abstract: Lagoa Santa region has been subject of archaeological studies since the first part of XIX ${ }^{\text {th }}$ Century. Known for the recurrent presence of human burials, rockshelter occupations and a chronology that dates back to Brazil's first occupation, this region has shown, in the last years, evidences of open-air occupation, with available dates for different periods along the Holocene. In this paper we explore the data related to one of those sites, specifically in relation to its lithic assemblage. From this data we discuss its formation process and its chonology, putting this site into a dynamic occupation system of the hole karstic region of Lagoa Santa.

Keywords: Lagoa Santa - Lithic technology - Open-air site.

\section{Referências bibliográficas}

ARAUJO, A.G.M.; NEVES, W.; PILO, L.; ATUI, J.

2005 Holocene dryness and human occupation in Brazil during the "Archaic Gap". Quaternary Research, 64: 298-307.

ARAUJO, A.G.M.; PUGLIESE, F.

2009 The use of non-flint raw materials by paleoindians in eastern South America: a Brazilian perspective. In: Sternke, F.; Eigeland, L.; Laurent-Jacques Costa, L-J. (Orgs.) Non-Flint Raw Material Use in Prehistory - Old prejudices and new directions. Oxford: Oxbow Books, v. 1939: 169-175.

BINFORD, L.

1979 Organization and formation processes: Looking at curated technologies. Journal of Anthropological Research, 35 (3): 255-273.

1980 Willow smoke and dog's tails: huntergatherer settlement system and archaeological site formation. American Antiquity, 45 (1): 4-19.

BUENO, L.

2007 Organização tecnológica e teoria do design: entre estratégias e características de performance. In: Bueno, L.; Isnardis, A. (Orgs.) Das Pedras aos Homens. Tecnologia Litica na Arqueologia Brasileira. Editora Argvmentvm, Belo Horizonte: 67-94.

HRDLICKA, A.

1912 Early man in South America. Smithsonian
Institution, Bureau of American Ethnology. Bulletin n.52, Washington D.C.

HURT, W.

1960 The cultural complexes from the Lagoa Santa Region, Brazil. American Anthropologist, 62: 569-585.

HURT, W.; BLASI, O.

1969 O projeto arqueológico "Lagoa Santa", Minas Gerais, Brasil. Arquivos do Museu Paranaense, Arqueologia, 4: 1-60.

LAMING-EMPERAIRE, A.; PROUS, A.; VILHENA

DE MORAES, A.; BELTRÃO, M.

1975 Grottes et abris de la region de Lagoa Santa, Minas Gerais, Bresil. Cahiers D'Archaeologie D'Amerique du Sud: 185.

MATTOS, A.

1946 Lagoa Santa man. Handbook of South American Indians I, The Marginal tribes. Bureau of American Ethnology Bulletin 143: 399-400.

MYERS, A.

1989 Reliable and maintainable technological strategies in Mesolithic of mainland Britain. In: Torrence, R. (Ed.) Time, Energy and Stone Tools. Cambridge, Cambridge University Press: 78-91.

NEVES, W.; GONZÁLEZ-JOSÉ, R.; HUBBE, M.; KIPNIS, R.; ARAUJO, A.G.M.; BLASI, O.

2004 Early Holocene skeletal remains from 
Cerca Grande, Lagoa Santa, Central Brazil, and the origins of the first Americans. World Archaeology, 36 (4): 479-501.

NEVES, W. ; GONZÁLEZ-JOSÉ, R.; HUBBE, M.; KIPNIS, R.; ARAUJO, A.G.M.; BLASI, O.

2004 Origens e Microevolução do Homem na América: uma abordagem paleoantropológica II. Relatório Cientifico, FAPESP.

NEVES, W.; ARAUJO, A.; CECCANTINI, G.; BUENO, L.; DE OLIVEIRA, P.; KIPNIS, R.

2008 Origens e microevolução do homem na América: uma abordagem paleoantropológica III. Relatório Cientifico, FAPESP.
SHOTT, M.

1994 Size and form in the analysis of flake debris: review and recent approaches. Journal of Archaeological Method and Theory, 1 (1): 69-110.

SULLIVAN, A.; ROZEN, K.

1985 Debitage analysis and archaeological interpretation. American Antiquity, 50: 755-779.

WALTER, H.V.

1958 Arqueologia da região de Lagoa Santa, Minas Gerais. Rio de Janeiro: Sociedade Editora e Gráfica Ltda. 